\title{
PARADIGM SHIFTS IN MEDICAL EDUCATION: IMPLICATIONS FOR MEDICAL/HEALTH LIBRARIANS IN SUB-SAHARAN AFRICA
}

\author{
Margaret Adeogun \\ University of Eastern Africa, Baraton, Eldoret, Kenya
}

\begin{abstract}
Contemporary health and medical education in the present information dispensation must actively engage healthcare providers in opportunities for knowledge seeking, learning to learn, and motivation to continue learning. The favored pedagogical design to achieve this is Problem-Based Learning (PBL) enhanced with the provision of library and information services that will enable health workers to acquire problem solving and lifelong learning capabilities. This paper presents a brief analysis of Problem-Based Learning features and their usefulness in medical and health education in Sub-Saharan Africa. In greater detail, it discusses the emerging roles of the medical/health librarian in the present knowledge dispensation. The new paradigm challenges information professionals to expand beyond traditional roles to designing and building quality knowledge management infrastructure that will provide access to quality-filtered, evidence-based, and critically analyzed information designed for use by healthcare trainers, students and consumers. In addition, the trend provides librarians with the opportunity to develop programmes for quality information instruction for healthcare professionals. The information professional is not only a collaborator in the research process and project management, but also facilitates immediate information access at the point of need for medicalhealth students, and also promotes public understanding of health issues through communication. Finally the paper discusses the measures that academic librarians can adopt in the successful implementation of PBL in their institutions.
\end{abstract}

\section{Introduction}

The need to adopt the ever-advancing biomedical research to medical practice has necessitated that healthcare givers acquire skills for selfdirected and independent learning. The demand is to adopt a more student-driven, problem-based approach to medical education so as to equip healthcare givers with skills to continue to learn throughout their professional life (Huttly et al, 2003:212). This suggests that medical education in the present knowledge dispensation requires a large-scale, intensive programme for integrating information-seeking skills and sources that will produce healthcare givers who are good problem solvers and life-long learners. People who are able to work productively in multidisciplinary teams, produce clinical knowledge and communicate well with their patients are preferred by the public and the health sector. In this regard, problem-based learning (PBL) 
pedagogy and learning approach has been widely accepted and adopted in many institutions offering medical/health education.

$\mathrm{PBL}$ is a learning methodology that incorporates problem solving, information seeking and lifelong learning features. It is a knowledgebased learning methodology and as such requires that students acquire information competency skills. These skills will enable them to develop the skills to locate, access, critically manage, evaluate and use information to make effective and responsible clinical decisions. At no time in history are such skills in high demand than in this information age characterized by expanding quantity of information in a variety of formats. And there are no other groups of professionals in medical training institutions that are better qualified to train students to acquire modern information management skills than librarians who, by their training, are highly skilled to impart such skills and knowledge.

The need of the PBL curriculum has therefore opened new and emerging roles for librarians as instructors in information literacy, providers of networked information resources and consultants on information management and coordinators of information technology applications. These are services that require new competencies beyond traditional librarianship. Librarians have to have increased knowledge; modern information management skills, analytical skills and creativity skills to enable them meet more contemporary information needs with multi-level and multi-functional capabilities (Ferreira, 2007: 4).

This paper addresses the emerging challenges that library professionals working in PBL environments face and discusses the strategies that can be employed to equip them with knowledge, skills and attitudes to perform efficiently in a knowledge-intensive world. In addition, the paper highlights the background and concept of PBL and the relevance of a PBL curriculum in Sub-Saharan Africa.

\section{Issues for Discussion}

\section{Historical background of PBL}

The PBL learning methodology emerged in response to criticisms that the conventional, didactic and faculty-centered medical health curriculum which relies heavily on lectures, assigned reading in textbooks and term papers are incapable of imparting self-directed, 
PBL is centered on identifying and defining a health problem, investigating and finding solutions to the problem. It operates on a case-base, small group learning usually in tutorial sessions. Each session is facilitated by a tutorial teacher, a librarian and others who guide the students to identify some clinical problems which will form the case study for the group. The group then brainstorms the case, formulates key research problems (hypotheses) for investigation, and defines both the human and information resources needed to explore the problem. Members of the tutorial groups then begin to collect the needed information from a wide variety of sources including libraries, archives, teaching staff and fellow students. Information gathered is then analyzed and synthesized and the findings are discussed and reviewed. This process enables students to draw on their own experiential knowledge, reflect on the process of their own thinking and knowledge-building (Watkins, 1992:309; Cleverly, 2003:115). Since learning is independent, learners determine and seek their own information resources. In the process, they acquire informationseeking skills which are fundamental to the PBL curriculum.

This method stimulates intellectual curiosity, extensive use of information resources and deep-level information processing. Naturally the PBL curriculum lends itself to a rich variety of resources, and the acquisition of information seeking and management skills by students. It thrives better in an information environment where knowledgeable, flexible, highly professional librarians are available and equipped to provide modern information management education services to medical/health students. It is in this context that the librarian embraces new roles that are changing the course of information services.

\section{PBL and new roles for libraries/librarians}

As medical/health training institutions embrace new models of instruction to produce lifelong learners and independent learners, particularly in the PBL environment, librarians are bracing up for new status as information specialists. It is their responsibility to equip medical/health professionals with life-sourcing and lifelong learning skills to tackle health problems in Sub-Saharan Africa. They are embracing new roles as a discipline or faculty with increased involvement in curriculum planning, and as instructors and facilitators of health information literacy. It is their responsibility to provide greater access to information resources and ensure that 
resources are optimally utilized. The extensive and long-term usage of library resources and facilities by PBL students require the provision of adequate library infrastructure.

\section{Increased educational involvement in curriculum planning}

Because information seeking skills and information management skills are crucial to the PBL curriculum, the librarian is involved in planning the content of the curriculum right from the beginning. Working collaboratively with the medical teaching staff and other staff on the curriculum planning committee, the librarian will provide greater input and insight in planning and designing the information management component and the information resources needed by students (Eaton and Richardson, 1993). This is particularly critical in an age characterized by new telecommunication technologies with increasing complexity in information. It is the role of the librarian to coordinate information technology applications, and facilitate resource sharing. The librarian works collaboratively with students and faculty to identify, and evaluate many information sources, structure research questions, clarify problems and identify relevant resources for solving a particular problem. The librarian in this sense is an information specialist offering consultancy services and playing a full and an active role in the instructional and research process of academics.

Because the PBL curriculum is relatively unstable and requires diversified resources, the librarian at the planning stage will need to coordinate the needed resources to support the frequently-changing needs of the PBL modules, and plan to provide greater access to information resources. In this respect, the Sub-Saharan medical and health librarians face a lot of hurdles in that their libraries are poorly stocked and they have very minimal cooperation with other institutions in sharing resources.

\section{Teaching roles for librarians}

As students in the PBL curriculum explore and utilize variety of information resources than others, they need to learn extensive information and computer management skills. A comprehensive library orientation in information literacy that provides training in accessing and managing information resources is an imperative. Such training will include instructions in computerized literature searching, problem-solving, and guidance on the utilization of a problem-based approach to information resources (Jackson and Parker, 1998: 176). 
Since students gather enormous information, they have to learn how to organize and retrieve this information. The librarian must therefore be prepared to teach some computer application packages such as Fox Pro, Lotus Approach, Microsoft Access, and many others.

Information literacy instructions are particularly planned and geared towards meeting the specific needs of each tutorial group and it should be provided at the point of need in the curriculum (Watkins, 1992). It is the librarian's role to collaborate with the medical / health teacher, the students and other facilitators in the tutorial group to construct and deliver relevant instructions that convey only the essential knowledge and skills that are needed to complete the group's assignment.

The librarian has to guide the process of formulating research questions into MeSH terms, direct the students in identifying and selecting relevant resources, teach skills in using health information sources, such as Permuted $\mathrm{MeSH}, \mathrm{MeSH}$ and Index Medicus (Eldredge, 1993:313).

The library instruction skills imparted to healthcare professionals foster self-reliance in using information resources meaningfully and effectively. They should equip healthcare professionals with the skills to package health information to meet the education and understanding levels of the communities that they serve. Such skills are central to healthcare providers who serve in rural areas. Through these services, the librarian is evolved not only into a key information resource, but also into a discipline-specific instructional faculty (Blake, 1994: 171)

\section{Librarians' preparedness for the implementation of PBL}

The previous discussion suggests that medical librarians' roles have extended from traditional librarianship into newer, more contemporary information service providers. The Medical Library Association's Platform for Change described the new roles of the medical librarian as "pivotal in the handling of biomedical information, combining the ability to use the knowledge bases of medicine and the technical expertise of librarians with clearheaded problems solving, analytical competence, and well-honed interpersonal and organizational skills."

(http://www.mlanet.org/education/platform/context.html) 
This statement implies that librarians need greater knowledge and information management skills that will enable them to provide information services to support the pedagogic needs of modern medical learning and instruction. The skills to teach information competency skills, facilitate problem analysis using information, serve as a discipline instructor, and coordinate curricular formulation are core competencies expected of any medical librarian.

\section{Improved education for medical librarians}

To perform their new roles effectively, medical librarians in SubSaharan Africa, must develop core competencies. These skills involve acquiring the relevant knowledge, capacities and abilities that will prepare them for multi-level and multi-functional information services. Core competencies are understood to mean "a proper attitude and capacity to exercise a wide number of functions or occupy various positions, even simultaneously, which requires flexibility." (Ferreira et al., 2007). With the increased importance of information, and the particular need of medical professionals to acquire information sourcing techniques, librarians need to equip themselves with scientific and technological information management skills to enable them dispense their services more competently in a continually changing information environment. Of the many options available for improved skills and knowledge for librarians, two of them stand out clearly: update their knowledge and skills through continuing training for improved professional development, and modification of library school curriculum to reflect new and emerging information services to society.

As far as initiatives for continuing training for librarians in health information services are concerned, there are many such initiatives world wide. One such initiative is the Partnerships in Health Information (Phi). This initiative has assisted many medical librarians to upgrade their skills in medical librarianship. Among the many beneficiaries of the Phi continuing training initiative are the librarians at the College of Medicine and Allied Health Library (COMAHS) in Sierra Leone and members of Sierra Leone Medical and Dental Association. Through the Cardiff University Library partnership with COMAHS, some librarians from Sierra Leone have benefited from further training in medical information services in the United Kingdom. 
Working collaboratively with Phi, Kent and Medway Health Authority provided ICT training for some librarians at Makerere University. Albert Cook Medical Library. The Kenyan Medical Research Institute (KEMRI) is in partnership with Avon, Gloucestershire and Wiltshire Workforce Development Confederation Health Library and Information Services for continuing training in health information services. These are just a few examples, there are several such initiatives and librarians need to take advantage of them.

Curriculum modification in library schools has become an imperative in view of the changing roles of librarians. Significant modifications are needed in the curriculum if library schools in the continent are to produce graduates with competences to address newer, more contemporary information needs. In these days when information literacy instructional skills are increasing in importance; and skills in scientific and technological information management are crucial, librarians need advanced skills in these areas. Health sciences librarians, in particular, need PBL skills. Studies (Dimitroff, et al, 1998:341, In Olander, 1995) emphasize that PBL highlights the problem-solving process and its central element such as informationseeking, analysis; critical assessment, structuring, and creativity are elements that should be introduced in the curriculum of health science librarians. Training in these skills will prepare them to perform their duties more competently and efficiently. Ferreira, et al (2007) observed that librarians in the information age need greater knowledge and skills. According to the authors, librarians need greater knowledge in information and communications technologies, modern information management, and in defining the relationship between the field of information and other fields. They need greater skills in interpersonal communication, teamwork, creativity and many others. These will prepare them for their roles as information specialists.

\section{Greater access to information resources}

Students in the PBL curriculum extensively use a wide variety of resources than their counterparts in the conventional curriculum. To meet their needs, the librarian must prepare to provide access to greater resources, and in particular, networked electronic information resources that can be readily accessed. This is a major challenge to medical libraries that are poorly stocked, a scenario that characterizes many medical libraries in Sub-Saharan Africa. The PBL librarian has 
the responsibility to support and press for initiatives that will enhance access to health information resources. There are many partnership initiatives within and outside the region that provide opportunities for increasing access to information resources. Notably among the many partnership programmes that have become very effective is the Partnerships ' in '. Health.. Information (Phi) (http://www.intute.ac.uk/healthand lifesciences/hosted/phi In addition to facilitating partnerships between health libraries for continuing training as mentioned previously, Phi also facilitates the provision of information resources to medical libraries. For example, through Phi, the University of Wales assisted the College of Medicine and Allied Health Library (COMAHS) in Sierra Leone in rebuilding their library after the civil war by providing computers, equipment, books and many other resources.

There are initiatives that provide medical information resources to the continent at reduced costs. Notably among them are the AGORA and HINARI initiatives. These initiatives have brought scientific publications to the living rooms and offices of academic researchers. The Programme for the Enhancement of Research Information (PERI) facilitated by International Network for the Availability of Scientific Publications (INASP) has provided access in ways that have never been experienced in African libraries, to seamless information resources not only for the health sector but also for the African researchers, who otherwise would never have been able to access such resources.

The Ptolemy Project aims at providing electronic health information in Africa and other developing world. It is in partnership with the University of Toronto, the Association of Surgeons of East Africa (ASEA), the College of Surgeons of East, Central and Southern Africa (COSECSA), and the Canadian Institute of Heath Research (CIHR) in providing access to full-text information resources of the University of Toronto library (http://www.ptolemy.ca). Librarians in East, Central and Southern Africa should urge their surgeons to register for the Ptolemy Project so that they can gain access to additional electronic resources.

The "Open Access" Initiatives

(http://www.soros.org/openacess/index/shtml) are opportunities that medical librarians should exploit. Among the many Web sites 
that provide free access to scientific and medical publications include the following:

http://www.doaj.org (Directory of Open Access Journals)

http://intl-CIRC.ahajournals.org (Medical journals)

http://www.malaria.org (Publications on Malaria)

http://pubmedcentral.nih.gov (U.S. National Library of Medicine digital archive of biomedical and life sciences literature)

http://www.flyingpublisher.com (A gateway to major credible medical and health information)

http://www/freemedicaljournals.com (Access to over 1450 medical journals)

http://www.freebooks4doctors.com (Full text access to over 650 current medical books)

These initiatives reduce the biomedical science information gap between the developed world and Sub-Saharan Africa. The accessibility that they provide fosters the research capacity of healthcare providers in the continent. Medical librarians as members of the healthcare community of professionals should explore more avenues for medical information resources and promote their usage for maximum healthcare benefits.

\section{Physical infrastructure}

PBL students spend a greater amount of time in the library and use the library more often than other students. Therefore physical facilities must be adequate and seating arrangement should be comfortable. The library should be open for longer hours or special arrangements could be made to allow long uninterrupted hours of study. Specifically PBL students need space for the following activities:

- $\quad$ networked presentation rooms with access to the Internet;

- lounges for individual and group study with Internet connections;

- collaborative work and study spaces, teleconferencing spaces;

- Shelves for reference and multimedia resources and

- Cafes for recreation.

\section{Conclusion}

PBL as a modern medical/health methodology poses significant challenges to librarians in Sub-Saharan Africa. The librarians have extended roles as educators and information coordinators. They are 
increasingly being involved in course planning and collaboration with the faculty in identifying information sources, designing and implementing clinical case studies. As more medical/health institutions shift from the lecture-based system to partial or full PBL methodology, medical librarians must demonstrate professional competence in modern medical information services and their skills must meet the continual changing environment in which they work. The increasing responsibilities of medical librarians, if taken seriously, will help to improve the training of healthcare providers in SubSaharan Africa and by implication to improved delivery of healthcare systems.

\section{References}

Akasha, A. (1995). "Settings for learning the community beyond." Medical Education, 29 (Suppl.1), 112-5.

Akpala, C.O. (1991). "Medical education and primary heath care in Nigeria: the Sokoto University experience." Central African Journal Medicine. November 37 (11), 374-7

Byrne, N. \& Wasylenki, D (1996). "Developing a social contract between the medical school and the community." Israel Journal of Medical Science, Mar-April 32 (3-4), 222-8

Cleverly, Dankay. (2003). Implementing inquiry-based learning in nursing. New York: Routledge.

de Villiers, M., Bresick, G., Mash, B. (2003). "The value of small group learning: an evaluation of an innovative CPD programme for primary care medical practitioners." Medical Education, Sept.37 (9), 815-21.

Dimitroff, A. et al. (1998). "Problem-based learning in a health sciences librarianship course." Bull Med Libr Assoc, 86(3), 340345.

Drake, J. (1994). "Library resources for problem-based learning: the program perspective." Comput Methods Programs Biomed, September, 44:167-73. 
Eldredge, J.D. (1993). "A Problem-based learning curriculum in transition: the emerging role of the library." Bulletin of Medical Library Association, July 81 (3), 310-315.

Evensen, D.H; Hmelo,Cindy E. (2000). Problem-based learning: a research perspective on learning interactions. Lawrence Eribaum Associates.

Ferreira, F, Santos, J.N., Nascimento, L., Andrade, R.S., Barros, S., Borges, J. et al. (2007). "Information professionals in Brazil: core competencies and professional development" Information Research, 12(2) Paper 299. [Available at http://InformationR.net/ir/12-2/paper299.html].

Huttly, Sharon; Sweet, John; and Taylor Ian. (2003). Effective learning and teaching in medical, dental and veterinary education. Sterling, Va: Kogan Page.

Iputo, J.E \& Kwizera, E. (2005). "Problem-based learning improves the academic performance of medical students in South Africa." Medical Education, 39(4), 352-3.

Jackson, M. and Parker, S. (1998). "The role of library and information services in supporting students in research-based learning: some findings of the IMPEL2 project." Journal of Further and Higher Education, 22 (2), 173-181.

Kirigia, Joses Muthuri, et al. (2006). "The cost of health professionals' brain drain in Kenya." BMC Health Services Research, Jul.17 (6), 89

Le Vigouroux, A. (2002). "A description of a community-oriented cum PBL post graduate training course for health districts managers in Central Africa." Education for Health, 15 (2), 158-65.

Lloyd-Jones, G.M. (2005). "Beyond tomorrow's doctor: a review of basic medical education in the U.K." Annals of Tropical Pediatrics, Jun. $25(2), 71-8$.

Marshall, G.J., Fitzgerald, D.F., Busby, L. \& Heaton, G. (1993). "A Study of library use in problem-based and traditional medical 
curricula." Bulletin of Medical Library Association, July, 81 (3), 299305.

McLean, M. (2004). "A Comparison of student who chose a traditional or a problem-based learning curriculum after failing year 2 in the traditional curriculum: a unique case study at the Nelson $R$. Mandela School of Medicine." Teaching \& Learning in Medicine Summer, 16 (3), 301-3.

Olander, B. (1995). "Problem-based learning in LIS education." Paper presented at the First British-Nordic LIS conference; May 22-24. Available on the Internet at: (http://epip.lut.ac.uk/bailer/24oland.htm).

Omer M.I. (2005). "Can Medical Education Rise to the Challenge of the African Crisis?" Annals of Tropical Pediatrics: International Child Health, Dec.25 (4), 227-41.

Rankin, J. A. (1992). "Problem-based medical education: effect on library use." Bulletin of Medical Library Association, 80 (1), 36-43.

Schilling, K., Ginn, D.S., Mickelson, P., and Roth, L.H. (1995). "Integration of Information seeking skills and activities into a problem-based curriculum." Bulletin of Medical Library Association, April, 83 (2), 176-183.

Uys, L.R.; Gwele, N.S.; Mclnerney, P.; Van Rhyn, L.; Tanga, L. (2004). "The competence of nursing graduates from problem-based programmes in South Africa." Journal of Nursing Education, 43(8), 352-61.

Wagstaff, Adam \& Claeson, Miriam. (2004). The Millennium development goals for health: rising to the challenges. Washington, D.C. World Bank.

Watkins, M.C. (1993). Characteristics of services and education programs in libraries serving problem-based curricula: a group self-study. Bulletin of Medical Library Association, July 81 (3): 306-9.

World Bank. (2006). Disease control priorities in developing countries. Washington, D.C.: World Bank. 